\title{
O uso da música jovem como instrumento para educação sexual
}

Junia Dias de Lima*

No verão de 2001, houve uma explosão de bailes funk no Rio de Janeiro com uso e abuso de letras altamente eróticas bastante distorcidas estimulando o exercício da sexualidade de forma muito irresponsável. Este tipo de música chamado pelos seus praticantes de "funk melody", não foi bem aceito nem dentro da comunidade de funkeiros e rappers, sendo inclusive denominado por MV Bill, respeitado rapper no Rio de Janeiro, de "funk bunda".

Nesta época, as manchetes dos jornais chamavam a atenção para "a dança do sexo nos bailes funk", "grávidas do funk preocupam prefeitura" ou ainda "culto à barbárie". Os trechos das músicas mais picantes também foram largamente divulgados. Eis alguns exemplos:

"Entra e sai, entra e sai. Na porta da frente e na porta de trás. Elas são maravilhosas, elas são maneiras" (Bonde do Tigrão).

"Bota na boca, bota na cara, bota onde quiser.

Bota tudo e faz gostoso" (Tati Quebra-Barraco).

* Ginecologista. Terapeuta e Educadora sexual. Delegada Regional da SBRASH no Rio de Janeiro. Coordenadora do Núcleo de Sexualidade da Mangueira (NESMA).

e-mail: cgodr@uol.com.br

Recebido em 02.04 .02

Aprovado em 17.04.02 
"Sou cachorra chapa-quente, adoro quando me tara.

Fico louca de tesão, pedindo tapinha na cara.

Eu sou gatinha manhosa...Que tesão, vou te arranhar" (As Mercenárias).

As adolescentes também recebem denominação segundo sua condição sexual. A "tchutchuca" é a mulher bonita, meiga e serve para namorar "a sério". Já a "cachorra" é aquela garota "liberada", que só anda com os funkeiros e "fica" com mais de um cara de uma vez. Existe ainda a "preparada", aquela que comparece aos bailes de saia curta, sem calcinha, disponível para as "brincadeiras do trenzinho" que são homens e mulheres que dançam enganchados em fila. Há relatos que no meio do baile é avisado de que a luz vai ser apagada e aí cada um faz o que desejar. Não podemos deixar de mencionar ainda a "potranca" ou "popozuda", que é a mulher gostosa com bumbum grande.

Analisando somente da perspectiva externa, as letras do funk têm um teor altamente machista e violento, sendo a mulher apenas objeto de conquista. Conversando com algumas delas sobre como se sentiam neste contexto, recebemos a seguinte explicação: "Vamos dar um exemplo: para vocês que não vivem na comunidade, a visão de um homem armado com uma macaca (metralhadora) é muito forte. Ficam todos assustados. Mas para nós que fomos criadas aqui, isto faz parte do cotidiano. Nós nunca subimos ou descemos o morro sem nos depararmos com vários deles". Continuam explicando que é a mesma coisa com relação ao funk. Para quem está de fora é difícil compreender o jogo, o ritual que existe nos bailes. As meninas não se sentem usadas, mas sim donas de sua sexualidade, provocantes, podendo falar o que têm vontade. Com isto ganham espaço dentro do grupo.

Buscando uma forma de comunicação que pudesse estar mais de acordo com as atividades usuais destes adolescentes, resolvemos utilizar of funk como instrumento de educação sexual. Durante nossa aproximação com o grupo e a cultura "funk", descobrimos uma outra expressão cultural muito forte nas comunidades de periferia, o hip-hop.

O hip-hop surgiu na Jamaica, nas comunidades de periferia de algumas cidades, na década de 1960 através do "sound systems", versão rudimentar do que hoje pode ser visto nos carros de trio elétrico do carnaval de Recife. Sem dinheiro, essa população dos guetos ia para as ruas, fazendo discursos e repetindo frases que denunciavam as carências e as violências sofridas. Na década de 1970, em virtude de vários problemas políticos e econômicos enfrentados pela ilha, houve intensa imigração para os Estados Unidos da América. Um desses imigrantes foi o DJ Kool Herc, que desembarcou em Nova York levando, assim, este tipo de ritmo, que se difundiria por todo o gueto. O hip-hop chegou ao Brasil em meados da década de 1980 por meio das equipes de black music. É uma expressão artística mais difundida nos estados de São Paulo e Rio de Janeiro. 
O hip-hop, como expressão cultural complexa que é, abrange aspectos musicais (o rap), visuais (o graffiti) e de dança (o break).

O rap é a expressão musical-verbal que tem como significado " $r$ hythm and poetry". É representado pelo DJ (disc jockey) e o MC (master of cerimony) também chamado de rapper. O DJ é aquele que manipula a "parafernália" do som, responsável pela batida e ao rapper cabe a colocação da letra na música.

A expressão visual deste movimento é manifestada através do graffiti. Em São Paulo, debaixo de um viaduto a expressão é definida por eles da seguinte forma: "Graffiti é sigilo, silêncio, anonimato, surpresa, inovação, ação, transformação, conteúdo, qualidade, intervenção, produção, atitude, estilo próprio e inteligência, linguagem universal... respeito".

O último elemento é o break, expressado através da dança na figura do Break-boy ou B-boy. É uma mescla de vários estilos como artes marciais, capoeira, mímica e sapateado, entre outras. Iniciou-se em Porto Rico como forma de protesto contra a guerra do Vietnã, sendo seus movimentos, por isso, referências à luta.

Unindo o funk e o hip-hop, instituímos, então, um concurso, o "Bonde da Cidadania" que teve como objetivo a produção de músicas pelos adolescentes com a condição de que tivessem como conteúdo letras que valorizassem a vida, a auto-estima, a cidadania, bem como, o sexo seguro.

\section{Utilização de recursos direcionados para a Educação Sexual}

Em novembro de 2000, foi fundado o NESMA - Núcleo de Sexualidade da Mangueira - sob o patrocínio da Delegacia Regional da SBRASH, no Rio de Janeiro. Esse núcleo tem como objetivo possibilitar o exercício consciente da sexualidade, principalmente entre adolescentes que sabidamente enfrentam problemas de grande magnitude como a gravidez inoportuna ou indesejável e a proliferação de doenças sexualmente transmissíveis que tanto ônus trazem para a sociedade.

A gravidez indesejável, especialmente entre adolescentes, não é um problema exclusivo de nossos dias, sendo encontrados relatos muito antigos, até mesmo no Velho Testamento, de práticas anticoncepcionais. Em nossos dias, no entanto, tem-se constituído em preocupação de profissionais e da sociedade em geral o crescente número de gestações indesejáveis e indesejadas, surgidas como um "efeito colateral" do exercício mais ou menos desorientado da sexualidade entre pessoas de todas as faixas etárias, mais ainda entre adolescentes que, pelas suas próprias características, na maioria das vezes, ainda não são capazes de avaliar e de assumir os riscos e as conseqüências da vida sexual ativa. 
Esse problema tornou-se de maior relevo a partir da década de 1960. Nessa época, como resultado da revolução dos costumes sexuais então ocorrida, houve liberalização do exercício da sexualidade, que resultou em aumento da freqüência de gestações indesejáveis e num recrudescimento das Doenças Sexualmente Transmissíveis.

Dentre os numerosos fatores que contribuíram para essa situação, dos mais importantes sem dúvida têm sido o uso e abuso da sensualidade nos meios de comunicação de massa e as visíveis mudanças nos costumes e na constituição das famílias, decorrente da acelerada urbanização. Além disso, ocorreu também uma perda da capacidade de controle sobre a sexualidade das jovens, pois o ambiente das grandes cidades não mais permite que nelas funcionem os tradicionais meios sociais e familiares de controle.

Tivemos, assim, nas últimas décadas, um meio social que estimula a todos, jovens e adultos, mas especialmente as mulheres adolescentes, ao início e exercício de vida sexual ativa, sem, no entanto, prepararem-se essas pessoas para o exercício consciente da sexualidade. Como seria de se esperar, essa situação resultou num grande aumento da freqüência de doenças sexualmente transmissíveis e de gestações indesejadas.

No Brasil, embora não existam estatísticas globais, dados do IBGE2000 nos dão conta de que ocorrem cerca de 600 mil partos adolescentes por ano, aos quais devemos acrescentar, no mínimo, outras 500 mil gestações que terminam em abortamento provocado, cujos registros fogem às estatísticas oficiais.

Outra cruel faceta do problema é a do filho socialmente indesejado. A inadequação social dessas crianças, muitas vezes abandonadas e mal amadas, é importante causa de mortalidade infantil e de delinqüência juvenil.

A maior freqüência de gestações inoportunas resultou num incremento de casos de abortamento provocado que, pelos riscos que traz, não é evidentemente uma opção desejável.

Mais especificamente na comunidade da Mangueira, tem-se observado elevado número de gestações inoportunas entre adolescentes, sendo que um levantamento prévio realizado no Posto de Saúde da Vila Olímpica mostrou que o número de gestantes adolescentes em pré-natal representa perto de $35 \%$ dos atendimentos, números esses ainda maiores que os referidos pela literatura nacional, que aponta como partos de mães adolescentes cerca de $25 \%$ do total.

Tal freqüência de gestações indesejáveis evidentemente acarreta um ônus social, claramente representado pelas dificuldades de acesso a Serviços de Assistência Pré-Natal, o que enseja elevados índices de morbidade e mortalidade perinatal.

Por outro lado, todos sabemos dos riscos advindos de uma sexualidade mais liberalmente exercida, sendo constatação comum o expressivo aumento das Doenças Sexualmente Transmissíveis (DST) entre a população com piores condições de Educação Sexual. Num levantamento prévio, 
empreendido junto ao Posto de Saúde da Vila Olímpica, na Campanha "Prevenção da Sífilis Congênita - 2000", evidenciou-se que 10\% das gestantes incluídas no estudo tinham reações sorológicas positivas para essa infecção.

\section{A estruturação do concurso}

A estruturação do concurso teve quatro comissões: organização, inscrição, seleção e julgamento (júri). As três primeiras foram constituídas pelos organizadores e por membros da comunidade da Mangueira. Para o júri (comissão de julgamento) foram convidados um ator, um professor de músi$\mathrm{ca}$, um diretor da escola de samba da Mangueira e um músico profissional. Os quesitos avaliados foram letra, ritmo, voz e postura de palco.

A primeira questão a ser resolvida pela comissão organizadora era a elaboração de um regulamento. Procuramos alguma base para a formulação deste quesito no concurso de samba enredo mas não havia qualquer semeIhança com aquilo que havíamos idealizado. Tivemos que elaborar tudo às escuras. Além disso, tínhamos que ter a aprovação do juizado de menores pois os bailes nesta época estavam sofrendo intensa repressão. Inicialmente, havíamos pensado realizar o concurso em um sábado às 20:00h, mas todos aqueles com quem falamos diziam já saber do "baile" no sábado à noite. Para descaracterizar o concurso como baile, marcamos o concurso, então, para a tarde de domingo, dia 6 de maio na quadra do Grêmio Recreativo Escola de Samba Estação Primeira da Mangueira. Resolvemos estabelecer como idade mínima para participação no evento 14 anos e como máxima 21 anos. Deveriam estar todos estudando ou, pelo menos, com o ensino médio completo. Para a inscrição, deveriam fornecer a letra da música datilografada em 5 vias, uma para cada integrante da comissão de seleção.

Com as diretrizes preliminares traçadas, iniciamos o trabalho de divulgação na comunidade. Pretendíamos divulgar em todo o Rio de Janeiro mas quando procuramos as lideranças comunitárias, fomos informados de que isso poderia causar vários problemas. A primeira informação foi a de que só as comunidades sob o mesmo comando de contravenção poderiam estar presentes, caso contrário, correríamos o risco de troca de tiros e brigas durante o evento. Fizemos pequenos cartazes que também só puderam ser distribuídos no morro, pois a colocação em outras comunidades, mesmo que da mesma facção, poderia ser vista como invasão de território. Fizemos anúncios em rádios comunitárias, o que nos trouxe grande retorno. Para convidar a população, um grande aliado foi o carro de som, circulando principalmente nos finais de semana, e faixas em locais estratégicos. Assim foi feita a divulgação.

Outros pontos a serem resolvidos eram as atrações e distribuições de brindes. Como atrações convidamos bandas iniciantes tanto de funk quanto hip-hop e um grupo de dança que se apresentaram durante o evento. A 
presença de $D J s$ também é vital. Conseguimos promover distribuição de brindes como CDs, bolsas e camisetas. Contamos também com a colaboração dos Amigos da Escola com a presença de um ator global e relógios para os vencedores.

E isto nos remeteu a uma outra questão, que era o prêmio do vencedor. Para quem está iniciando, a melhor recompensa é ver sua música gravada em estúdio e foi isto que conseguimos para o melhor grupo.

Não se pode esquecer da estrutura de palco, apoio e segurança. Para isto, tivemos que estruturar uma equipe técnica formada por pessoas da comunidade, profissionais de música e dança que nos auxiliaram nas questões técnicas como som - a base de tudo - iluminação, palco, apresentação e evolução do evento.

Com isto resolvido, começaram a chegar as inscrições. Para nossa surpresa, a maior dificuldade enfrentada pelos potenciais inscritos foi a de entregar a música datilografada em cinco vias. Desistimos, então, deste pormenor e passamos a aceitar também textos em letra de forma, ficando para a comissão de inscrição a tarefa de fazer as cópias necessárias.

Um dia, chegou um rapaz, todo cheio de ginga para fazer a inscrição. Quando questionado sobre a letra da música, disse que estava na mente. Como precisávamos da letra para a seleção e frente à dificuldade do jovem em colocar os versos no papel, colocamos um membro de apoio para escrever a letra que ele cantava. A música tem como título "O Rap do ai meu Deus”. Este jovem é um ex-menino de rua e a letra fala de injustiças sociais e esperanças.

Neste momento, nos demos conta de que, ao exigir escolaridade dos participantes estaríamos excluindo aqueles que jamais haviam sido incluídos em nossa sociedade. Com isto, estaríamos perdendo um inestimável material que a vida ensinou a estes jovens. Sabemos que nem tudo se aprende nos bancos da escola. Por isso, cortamos também este item do regulamento.

Das 20 músicas inscritas foram selecionadas 10 letras que, a luz dos critérios da comissão de seleção, pareceram as mais representativas.

\section{A análise das músicas}

Fizemos uma seleção de parte das músicas que conquistaram os primeiros lugares, por julgarmos serem as que mais evidenciam os problemas enfrentados pela comunidade bem como a proposta de seus autores, que utilizam a música como instrumento de conscientização.

Pensamos ser necessário reproduzir apenas os trechos mais significativos de cada letra, visto serem as mesmas, em geral, muito extensas. Tais excertos falam por si mesmos. 


\section{$1^{\circ}$ lugar-Filho dessa terra}

Sou um filho dessa terra, um Mc

Levando respostas positivas para o meu povo nunca desistir

Sou negro de mente incomparada

Jamais manipulado sujeito a humilhações

Retaliações do sistema

Brasil racista. País capitalista

A minha mensagem será fulminante

Entrará em sua mente

Como um bandido toma de bicho um morro

Meu código Morse será propagado por toda a nação

Mostrando ao povo pobre o poder em nossas mãos

Negão contra negão

O plano certo pra deixar meu povo em extinção

O sangue do povo preto não tem preço

Morrendo dia-a-dia na mão do governo

Lágrimas e ódio não trarão de volta

$\mathrm{O}$ que uma arma tirou

O hip hop vem da alma vem do coração

$\mathrm{O}$ Mc é um soldado de fuzil na mão

Com microfone eu levo a rima

Em cima da batida

Para os morros, asfalto e periferia

2ํlugar - Primeira Dama da Favela - Thales Vinícius

Toda menina no passado

Sonhou com um príncipe encantado

Hoje em dia na favela

É com bandido trepado

Sonho de menina toda entusiasmada

Ela quer ir para o baile

E se sentir bem arrumada

Seu pai e sua mãe

Trabalham pra caralho

E no final do mês não vê a cor do salário

Tudo o que ela pede seu pai se esforça

Se desdobra no mês

Deixa de comer para dar roupa de marca

Cansada de ouvir sua mãe reclamar

Ela quer uma vida melhor, mas não quer trabalhar

Nem pensa em estudar e só quer vadiar 
O patrão já falou

Quero ela no meu colchão

Corpo de mulher mente de criança

Valores inversos não há esperança

Foi traída pelo brilho do fuzil do patrão

Chamou e ela não resistiu

Não conseguiu dizer não

É uma criança

Sua vida vai mudar vai virar mulher

Quatorze anos que vão lhe marcar

Seu tempo de moça não vai mais voltar

Até aí está tudo bem mais a barriga está crescendo

Está vindo o neném

Sua mãe se desesperou, seu pai não aceitou

Pega a sua roupa e vai morar com seu marido agora

Isso para não fazer uma loucura e te espancar no meio da rua

Cadê suas amigas para te dar apoio, saíam contigo

Iludida com roupa e sapato

As garotas na favela não querem saber do perigo só querem saber de ser mulher de bandido

Esqueça essa vida de movie star ser mulher de bandido é correr perigo

Primeira dama da favela ela não quer este título vai voltar para a casa dos seus pais e pedir perdão por tudo que fez e seu pai a aceitou outra vez

Ela precisa pensar no seu filho o sangue que corre na sua veia é do pai que hoje está na cadeia

Você não é objeto para ser usado esqueça o título de primeira dama na favela as garotas estão iludidas por favor não seja uma mulher da vida

Não aceite esta posição você não é objeto para passar de mão em mão

Se você não se ama quem é que vai te amar?

Primeira dama da favela para ela não dá...

3o lugar-Rap do ai meu Deus... - Mc Sasá

21 trabalhadores morreram em Vigário Geral

e 7 inocentes morreram na Candelária.

Ai meu Deus, eu não vou pedir demais, Só peço ao senhor tranqüilidade e muita paz 
Sem essa de briga, sem essa de confusão

O mundo é muito lindo e viver é muito bom

Quem manda é a Manga, esse é o rap sangue bom

Eu não sei porque as guerras entre as comunidades, Eu não sou traficante, nem malandro de verdade E se você é forte e grande, larga a tua habilidade

Mas foi lá na Candelária, que morreram 7 amigos meus

Eles estavam dormindo e acordaram assustados, Olharam para o alto e viram uns caras encapuzados Não tem para onde correr e não tem como parar Já era a tua vida e sua morte vai chegar

Eu já fui menor de rua e não tinha onde morar, Parei em Copa e dormi em qualquer lugar,

Sobe um balão cheio de esperança

Os fogos explodindo no sorriso das crianças,

Felicidade nos bailes tem em qualquer lugar.

\section{O que são as comunidades e seu código moral}

As comunidades começaram a surgir no Rio de Janeiro no início do século XX. A história da comunidade Mangueirense começa com a ocupação do morro, cujo proprietário, o Visconde de Niterói, o recebeu como presente do Imperador Pedro II, em 1902. Em 1908, o morro agrega um outro grupo, constituído por militares expulsos da Quinta da Boa Vista. Em 1916, chegava um terceiro contingente, pessoas que foram expulsas por um incêndio de seus casebres do Morro de Santo Antonio, no centro da cidade. Assim surgiu, no morro da Mangueira, uma comunidade de gente pobre, constituída quase que na totalidade por negros, filhos e netos de escravos, inteiramente identificada com as manifestações culturais e religiosas que caracterizavam esse segmento social e étnico.

Um dessas manifestações culturais foi a música, mais precisamente o samba, que contava com a figura de Cartola, que, com seu tino político, conseguiu unir os principais representantes deste ritmo na época: Mangueira, Estácio e Portela. As reuniões musicais com samba que mereciam maior destaque eram as promovidas por senhoras baianas, conhecidas como tias. De todas, a Tia Ciata é considerada a mais famosa e importante, pois foi em sua casa que nasceu o samba carioca. Mas, nesta época, estas mesmas tias mantinham um rígido código de conduta. Quem fosse de muitas mulheres, bebida e farras era afastado do grupo. 
É bastante interessante o fato de que o principal veículo de intercomunicação entre a música popular e a elite, antes do advento do fonógrafo, tenha sido o assobio. Os trabalhadores, gente simples das ruas ouviam as músicas dos salões e teatros e se encarregavam de difundi-las, incluindo suas interpretações pessoais.

Na década de 1930, o samba carioca vira símbolo nacional. Estávamos sob o regime autoritário de Vargas e havia setores, como as forças armadas e o sindical, que começavam a se rebelar. Surgiam várias denúncias de discriminação racial e o samba foi utilizado por Vargas como propaganda para mostrar a autoconsciência do Brasil como um país de população miscigenada.

A comunidade toma grande vulto, nas décadas de 1940 e 1950, quando milhares de pessoas deixam o campo com o sonho de uma vida melhor na “cidade grande". É a invasão nordestina. Nesta época, a contravenção é representada pela figura do malandro, que só andava de terno de linho impecável, com seus seguranças. Traficavam apenas maconha, mas não era permitido que o consumo ou venda acontecesse na frente das casas dos trabalhadores da comunidade. Não só a comunidade era respeitada, como protegida. Eles mandavam avisar nos tanques de lavar roupa das mulheres no sopé do morro que eram para se recolherem cedo nos dias de conflito.

E aí veio a Revolução de 1964 e o AI-5. A repressão político ideológica mistura nos porões das prisões cariocas estudantes, a elite intelectual e bandidos comuns. Há trocas de experiências e é neste caldeirão de opressão, ódio e sofrimento que se organizam os estatutos da Falange Vermelha, em 1968, nas celas do presídio da Ilha Grande. O slogan criado foi "Paz, justiça e liberdade". Nos anos seguintes o idealismo político vai se perdendo e a violência passa a imperar, motivando a troca de nome para Comando Vermelho (CV). A contravenção tem agora organização, diretrizes e conhecimento de táticas de guerrilha.

Todo o código de conduta é modificado. As regras são rígidas e quem não as cumpre sabe que as punições ocorrerão de acordo com a gravidade da infração. Segundo as estatísticas policiais, o CV é a facção que mais mata. Não só mata, mas o faz com requintes de tortura, para mostrar força e disseminar medo. Os que têm punição mais severa são os alcagüetes e os traficantes que roubam dinheiro do chefe. São queimados vivos em tambores de óleo ou entre pneus. As penas variam com a gravidade do delito. Aqueles considerados fofoqueiros tem punição suave como raspar a cabeça. Já os pequenos furtos podem ser punidos com uma surra ou com uso de palmatórias com pregos.

Ou seja, o morador tem que ser "surdo-mudo-cego", impera a lei do silêncio. Fica exposto a todo tipo de violência, não só dos traficantes do morro, mas de invasores de outros grupos ou mesmo da força policial. Na comunidade, ninguém se esquece de uma invasão que houve há uns cinco anos, em que as noites eram de tiros, gritos de agonia e desespero. Passavam 
as noites em claro, atemorizados. Pela manhã, os corpos não podiam ser removidos, entrando em decomposição a céu aberto.

Vivendo dentro deste contexto, perguntamos para o grupo do hip-hop, o que este movimento significa para eles. A resposta unânime é a de que é um desabafo: da falta de perspectivas, das injustiças sociais, do racismo, enfim, de todo tipo de violência a que estão expostos e não conseguem fugir.

É este quadro de violência que permeia toda a vida do morador de comunidade. Segundo Aranha (1997, in Kuptas, 1997), a violência existe quando alguém é privado daquilo a que tem direito, provocando sofrimento, dor ou quando sua humanidade é diminuída. Há dois tipos de violência a ser enfrentada. A primeira é a chamada "vermelha", por haver derramamento de sangue. A segunda é a "branca", mais insidiosa e menos percebida, como a fome "oculta" do brasileiro com uma alimentação sem proteínas e vitaminas, prejudicando seu desenvolvimento físico-mental, motivada pela má distribuição de renda entre os cidadãos.

\section{As questões de gênero e a política da palavra}

As relações interpessoais, tanto entre pessoas do mesmo sexo quanto entre homens e mulheres, são permeadas pela violência. As mortes por assassinato são 15 vezes mais freqüentes dentre homens do que dentre mulheres, mas, no âmbito familiar, a situação da mulher, hierarquicamente inferior na escala de poder, é mais delicada. Esta afirmação pode ser melhor compreendida da perspectiva teórica de Saffioti (1997), que compara o domicúlio humano com o galinheiro. A organização de poder em um galinheiro é hierárquica, representado pela "ordem das bicadas". O maior poder é sempre do galo. Ele não só detém a posse sexual sobre todas as galinhas, mas também tem o direito de bicá-las, isto é, praticar violência. Entre as galinhas também há uma ordem. A favorita só pode ser bicada pelo galo, mas pode bicar todas as outras. A número dois sofre bicadas do galo e da favorita, mas pode bicar as demais e assim sucessivamente. A última na escala sofre bicadas do galo e de todas as demais galinhas, não tendo o direito de bicar nenhuma. Esta última galinha até pode ser comparada à mulher das comunidades carentes, excluída do mercado de trabalho, dos direitos do cidadão, enfim, dos direitos humanos mais elementares. É impressionante como a auto-estima entre estas mulheres é baixíssima. Para elas, ter alguém que não as deixe morrer de fome já é o suficiente. Elas aceitam sem discutir qualquer situação. Até mesmo os maus tratos corporais. Cabe estabelecer a diferença entre consentir e ceder. A mulher só pode consentir se ocupar o mesmo patamar de poder que o homem. Como é socialmente inferior, não consente, cede.

As histórias tristes são infindáveis. Ouvimos, recentemente, uma história que é bem ilustrativa dessa situação. No último mês, em um comunidade carioca, uma menina de 17 anos foi espancada com uma barra de ferro 
e, depois, morta com arma branca em frente a sua casa. O mentor do crime foi seu namorado, traficante do morro. Toda a vizinhança estava presente, $\mathrm{e}$ sua mãe implorava ao rapaz que parasse de espancá-la. Ele a julgou e condenou à morte simplesmente porque foi informado por uma amiga que ela havia conversado com um ex-namorado. A versão dela não foi ouvida. A lei do silêncio impede que qualquer queixa seja formulada. É mais um crime impune.

Esta adolescente entrou no jogo do tráfico com regras rígidas de conduta de gênero. Nelas, homens podem ter quantas mulheres desejarem mas as mulheres devem ser absolutamente fiéis, o que significa que não podem nem olhar para outro homem. Todas as mulheres que entram neste submundo sabem dos riscos, mas os aceitam basicamente pela mistura de baixa auto-estima e falta de perspectiva. Deve-se ressaltar que aceitar não eqüivale aqui a consentir e sim ausência de alternativa.

Este universo é muito bem retratado na música "Primeira Dama da Favela", apresentada em linhas acima. E não é só aí que o rap mostra sua capacidade de reagir à violência denunciando esta situação. O movimento do hip-hop atua também de forma muito positiva entre seus participantes. Muitas vezes eles conferem identidade humana ao reconstruir auto-estimas estilhaçadas pela sociedade.

É o caso de Ana, uma adolescente que vivia sem rumo e sem perspectivas. Entrou para um grupo de dança e viu aí possibilidades de progredir. Com família pobre, tinha que trabalhar para ajudar no sustento da casa. Trabalhava de dia, estudava à noite $\mathrm{e}$, depois da escola, ia treinar as coreografias. Chegava em casa, no morro, de madrugada, o que constitui um grande risco. Tinha um sonho e aceitou correr os riscos para alcançá-lo. Fez testes com um grupo de dança e foi selecionada para ir para a Turquia. Lá, não só trabalhou e ganhou dinheiro, mas hoje tem certeza de que tem potencial, que é gente, e, por isso, tem que ter seus direitos de cidadã respeitados.

Outra história que conhecemos foi a de uma adolescente, que também entrou para um grupo de dança de hip-hop, no qual conheceu um rapper, atualmente seu namorado. Ele é diferenciado dos outros homens da comunidade, porque tem dinheiro sem ser do tráfico. Então, pode levá-la para passear, lanchar fora, ir ao cinema, diversões raras para as mulheres desta comunidade. O problema é que agora ele diz estar com ciúmes dos rapazes do grupo de dança e quer que ela saia do hip-hop. Aí também impera o machismo, pois ele a colocou diante da seguinte opção: ou hip-hop ou o término do relacionamento. Agora, ela vai ter que optar entre um "bom" partido e a possibilidade de crescimento e trabalho com a dança. Não sabe ainda o que vai fazer e, por enquanto, continua treinando às escondidas.

Nas comunidades e mesmo dentro do hip-hop, a violência de gênero é sustentada pela ignorância, deseducação e machismo, que criam um ambiente em que a mulher se acha ser inferior, conformada e resignada com a sina de nascer com esse sexo, sem força interior de reação. Essa situação só vai mudar quando mais mulheres forem tomando consciência de seus direitos, pois a partir deste momento não negociarão mais sua liberdade. 


\section{Conclusões}

Para estarmos capacitados a trabalhar com educação sexual, principalmente com população carente, tem que haver uma disposição interna de olhar e ver a cultura do contexto em que nosso educando se insere. Não podemos utilizar, como educadores, os modelos éticos, morais ou religiosos pessoais. Precisamos estar abertos para conhecer o modo de viver e sobreviver, as crenças, os mitos e os tabus de nosso aluno para, do ângulo deste conhecimento podermos intervir positivamente, respeitando os limites dados pelas vivências individuais.

Segundo Vital Didonet, "Para você me educar, precisa me encontrar lá onde eu existo, quer dizer, no coração das coisas, nos mitos e lendas, nas cores e nos movimentos, nas formas originais e fantásticas, na Terra, nas estrelas, nas forças dos astros, do sol e da chuva. Precisa estar comigo onde eu estou, mesmo que você venha de longe e que esteja muito adiante" (Didonet, 1982).

A construção do ato de educar utilizando a expressão cultural do hiphop mostrou-se bastante eficaz, por meio da música, idéias e possibilidades de conduta foram passadas aos jovens pelos jovens. Segundo Vitiello (2000), a educação sexual, embora possa passar pelas instâncias de informação, orientação e aconselhamento, é no sentido mais amplo, a formação de condições e meios para que o educando cresça interiormente, assumindo comportamentos e desempenhando seu papel sexual. Só se mudam comportamentos mobilizando emoções.

$\mathrm{O}$ movimento do hip-hop é apenas uma possibilidade em um leque imenso, que abrange todas as expressões artísticas de nosso povo. Quanto mais engajados no mundo de nosso educando, mais simples e eficaz poderá ser nossa atuação. Não precisamos inventar novas formas de comunicação com o adolescente, mas sim aproveitarmos aquelas que eles já utilizam.

\section{Referências Bibliográficas}

ARANHA, M. L. A. Violência e Cidadania. In: KUPTAS, M. (org.). Violência em Debate. São Paulo: Editora Moderna, 1997.

ARAÚJO, V. Tráfico impõe código de conduta nos morros. Jornal O Globo, folha 20, 20/01/02.

DIDONET, V. Boletim Oficial da OMEP-Brasil, Rio de Janeiro, $\mathrm{n}^{2} 3$ a 5, ano 1982. LIMA, P. M. Polícia vai fazer blitz no funk. Jornal O Dia, folha 10,9/3/01.

SAFFIOTI, H. I. B. Violência doméstica ou a lógica do galinheiro. In: KUPTAS, Márcia (org.). Violência em debate. São Paulo: Editora Moderna, 1997.

SITE DA INTERNET: www.realhiphop.com.br.

SOVIK, L. O rap desorganiza o carnaval: globalização e singularidade na música popular brasileira. Caderno CRH, Salvador, n. 33, p. 247-55, jul./dez. 2000.

VITIELLO, N. Sexualidade, quem educa o educador. São Paulo: Editora Iglu, 2000.

WANBIER, A. Grávidas do funk preocupam prefeitura. Jornal Folha de São Paulo, Caderno C, folha 1, 9/3/01. 